\title{
Fe-Gd-Nb (Iron-Gadolinium-Niobium)
}

\section{Raghavan}

An isothermal section for this system was determined by $[1995 \mathrm{Zhu}]$ at $500{ }^{\circ} \mathrm{C}$. This section depicts one ternary compound $\mathrm{GdFe}_{11} \mathrm{Nb}$.

\section{Binary Compounds}

An updated version of the Fe-Gd phase diagram is given by [1998Zha]. There are four line compounds in this system: $\mathrm{Fe}_{17} \mathrm{Gd}_{2}, \mathrm{Fe}_{23} \mathrm{Gd}_{6}, \mathrm{Fe}_{3} \mathrm{Gd}$, and $\mathrm{Fe}_{2} \mathrm{Gd}$. [1993Bej] reinvestigated the $\mathrm{Fe}-\mathrm{Nb}$ phase diagram. The homogeneity ranges of the compounds of this system, $\mathrm{Fe}_{2} \mathrm{Nb}$ and $\mathrm{Fe}_{7} \mathrm{Nb}_{6}$, used in this review are taken from their work. There are no intermediate phases in the Gd-Nb system and the mutual solubility between $\mathrm{Gd}$ and $\mathrm{Nb}$ is negligible.

\section{Ternary Isothermal Section}

With starting metals of purity $99.95 \% \mathrm{Fe}, 99.9 \% \mathrm{Gd}$, and $99.9 \% \mathrm{Nb},[1995 \mathrm{Zhu}]$ melted 133 alloy samples in an induction furnace under Ar atm. The alloys were homogenized at $800{ }^{\circ} \mathrm{C}$ for 40 days and annealed further at $500{ }^{\circ} \mathrm{C}$ for 10 days; they were then quenched in an ice-water mixture. The phase equilibria were studied mainly by $\mathrm{x}$-ray powder diffraction. Their isothermal section at $500{ }^{\circ} \mathrm{C}$ is redrawn in Fig. 1 to agree with the accepted binary data. One ternary compound $\mathrm{GdFe}_{11} \mathrm{Nb}$ (denoted herein 1:12) is present at this temperature. This compound has the $\mathrm{ThMn}_{12}$-type tetragonal structure. The maximum solubility of $\mathrm{Gd}$ in $\mathrm{Fe}_{2} \mathrm{Nb}$ and
$\mathrm{Fe}_{7} \mathrm{Nb}_{6}$ and that of $\mathrm{Nb}$ in $\mathrm{Fe}_{17} \mathrm{Gd}_{2}$ are 1.8, 1.2, and 2.1 at.\%, respectively [1995Zhu].

It is interesting to compare Fig. 1 with the isothermal section at $\sim 25{ }^{\circ} \mathrm{C}$ determined by [1998Hua] (reviewed by [2000Rag]). At $\sim 25{ }^{\circ} \mathrm{C}$, two ternary compounds, $\mathrm{GdFe}_{11.4} \mathrm{Nb}_{0.6}(1: 12)$ and $\mathrm{Gd}_{3}(\mathrm{Fe}, \mathrm{Nb})_{29},(3: 29)$ are present. Also, in samples annealed at $700{ }^{\circ} \mathrm{C},[1998 \mathrm{Hua}]$ found both compounds. On the other hand, the isothermal section at 500 ${ }^{\circ} \mathrm{C}$ (Fig. 1) depicts only the 1:12 phase. [1998Hua] noted that the 3:29 compound in other similar systems such as Fe$\mathrm{Nd}-\mathrm{Ti}$ is stable only at elevated temperatures in contrast to its stability at room temperature found by them in the FeGd-Nb system. Clearly, the results of [1995Zhu] and [1998Zha] are contradictory and further experimental evidence is required to conclude whether the 3:29 phase is stable at low temperatures.

\section{References}

1993Bej: J.M.Z. Bejarano, S. Gama, C.A. Ribeiro, and G. Effenberg: Z. Metallkd., 1993, vol. 84 (3), pp. 160-64.

1995Zhu: Y. Zhuang, J. Huang, and H. Zhou: Z. Metallkd., 1995, vol. 86 (4), pp. 253-55.

1998Hua: F. Huang, J.K. Liang, Q.L. Liu, X.L. Chen, and G.Y. Huo: J. Phys.: Condens. Matter, 1998, vol. 10, pp. 9183-88.

1998Zha: W. Zhang, C. Li, X. Su, and K. Han: J. Phase Equilibria, 1998, vol. 19 (1), pp. 56-63.

2000Rag: V. Raghavan: J. Phase Equilibria, 2000, vol. 21 (5), pp. 454-55.

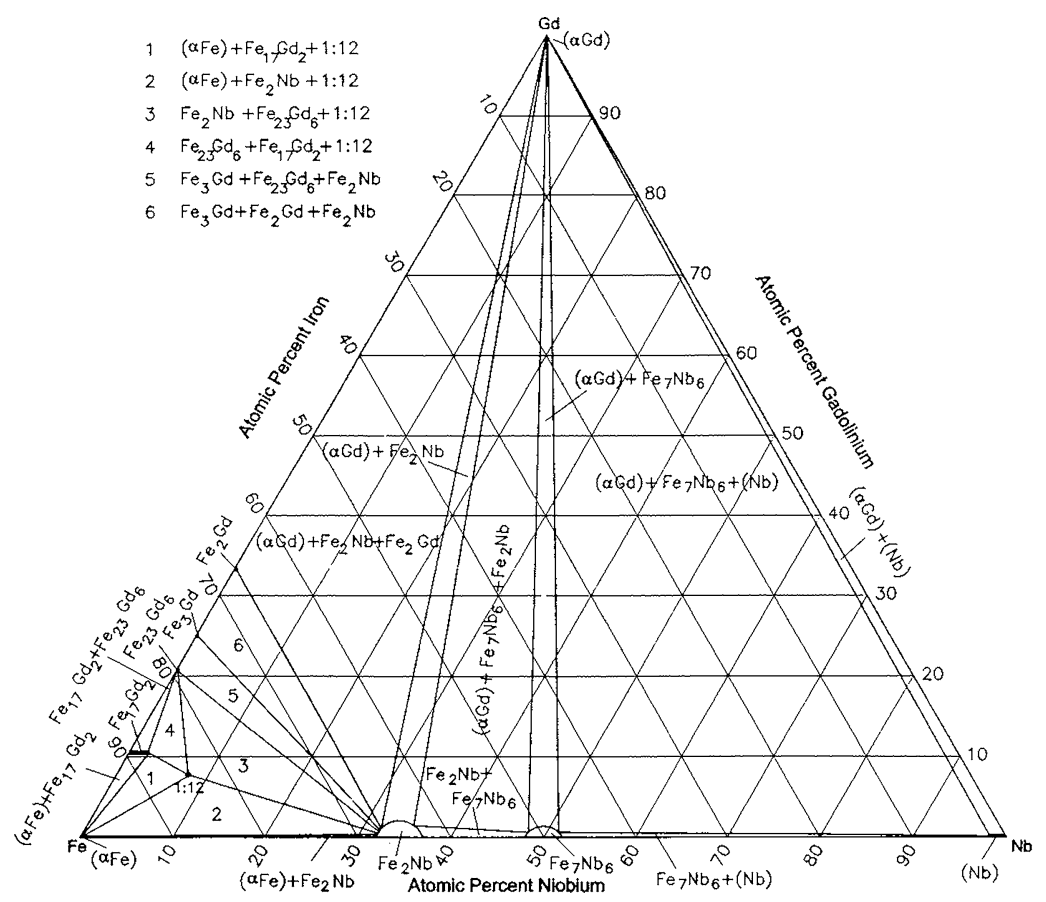

Fig. 1 Fe-Gd-Nb isothermal section at $500{ }^{\circ} \mathrm{C}$ [1995Zhu]. The thin two-phase fields around tie-triangles are omitted 